\title{
Surface Alterations to Impart Antiviral Properties to Combat COVID-19 Transmission
}

\author{
Reshma Y. Siddiquie ${ }^{1} \cdot$ Amit Agrawal $^{1} \cdot$ Suhas S. Joshi ${ }^{1}$
}

Received: 19 April 2020 / Accepted: 29 April 2020 / Published online: 14 May 2020

C Indian National Academy of Engineering 2020

\begin{abstract}
A global epidemic caused by highly transmittable COVID-19 is causing severe loss of human life. In this study, two aspects of reducing transmission of COVID-19 virus, due to surface contact, are discussed: first refers to the effect of nanocarbon fullerene $\mathrm{C}_{60}$ coating on surface, that causes lipid peroxidation on the phospholipid layer present in the outer envelope of COVID-19; the second aspect refers to creating hydrophobic surfaces by texturing them, so that the contact area between virus and surface is minimized due to the presence of entrapped air between the topographies. These can be similar to micro-/ nano-multiscale textured surfaces that have anti-biofouling properties. Fullerene-coated surfaces can be seen as a possible solution to decrease the adhesion of virus on the surface, as they will be hydrophobic as well as toxic to the envelope.
\end{abstract}

Keywords COVID-19 transmission $\cdot$ Lipid peroxidation $\cdot$ Hydrophobic surfaces $\cdot$ Fullerene $\mathrm{C}_{60}$ coating

\section{Introduction}

The current global epidemic declared by WHO is COVID19, which has infected over 2 million people and caused more than hundred fifty thousand deaths until this date (WHO Situation Report 2020a). An outbreak that has a transmission rate $\left(R_{0}\right)$ of less than one gradually decreases with time. In the case of COVID-19, the transmission rate is between 3.6 and 4.0 (Zhao et al. 2020); therefore, it is considered as a pandemic. The transmission of the COVID19 has a zoonotic origin and is like any other respiratory infections. There are two modes of transmission: first is through respiratory droplets, and the second is through contact routes (Tong et al. 2020; Liu et al. 2020; Huang et al. 2020). The respiratory droplet transmission is due to coughing or sneezing by an infected person to another healthy person within a range of $1 \mathrm{~m}$. This type of transmission can be avoided by keeping a reasonable distance between the people and by not coughing or sneezing in open air. The viability of the COVID-19 virus is approximately $3 \mathrm{~h}$ in the air (Editor Letter 2020); therefore, it is recommended to use a mask to avoid transmission. Another form of transmission

Suhas S. Joshi

ssjoshi@iitb.ac.in

1 Department of Mechanical Engineering, Indian Institute of Technology Bombay, Mumbai 400076, India is through contact route, in which the infected person somehow transmits the virus on a surface. This mode of transmission depends upon surface stability, which is the time duration of a material that can hold the virus. The surfaces show an exponential decay in the viability of the virus. The coronavirus can sustain up to $72 \mathrm{~h}$ on surfaces like plastic and steel, whereas it is less likely to be stable for such duration on copper and cardboards (WHO Situation Report 2020b; Editor Letter 2020). A favorable surface or high surface stability helps in the transmission of COVID-19 virus; therefore, research in the direction of reducing this surface stability is highly desirable.

In the past, some studies have shown that nanoparticles, particularly silver or nanocarbons, are toxic to both bacteria and viruses, because they cause chemical changes in the outer layers of the microbes (Sayes et al. 2005; Gacem et al. 2020). In other studies, researchers have analyzed these surfaces with the focus to create antiviral surfaces. Some of them had suggested that antibacterial or anti-biofouling surfaces are expected to have antiviral properties (Matsumoto et al. 2019). These properties are also demonstrated by hydrophobic surfaces. Because of the low surface energy of these hydrophobic surfaces, attachment and further adhesion of any microbes get reduced. To understand how the nanoparticles are toxic to the viruses, we have to analyze 
the structures and composition of the coronavirus family as discussed below.

\section{Structure of COVID-19}

COVID-19 belongs to the coronavirus family of Genus- $\beta$ which has 30-40 species (Schoeman and Fielding 2019). It is the seventh coronavirus which affect human, fifth and sixth being severe acute respiratory syndrome (SARSCoV) observed during 2002-2003; and Middle East respiratory syndrome (MERS) still being observed from 2012. All the three viral infections possess similar symptoms of fever and cough, followed by respiratory tract disease (Schoeman and Fielding 2019). The genome sequence of COVID-19 is much closer to SARS-CoV with an $88 \%$ match (Phan 2020). The genome of coronavirus family has four main structural proteins having different functions. The first is spike (S) protein; it is mainly involved in the attachment of virus into the host cell (Kirchdoerfer et al. 2016; Song et al. 2004). The second structural protein is the nucleocapsid $(\mathrm{N})$ protein that gives a response to the host cell and engages in the replication cycle (McBride et al. 2014). The third major structural protein is the membrane (M) protein that determines shape of the cell (Neuman et al. 2020). The last structural protein is envelope (E) protein; it is hydrophobic viroporins and is the smallest of all structural proteins with 76-109 amino acids (Venkatagopalan et al. 2015). The outer layer of viroporins consists of hydrophobic phospholipids (Schoeman and Fielding 2019). Therefore, the outer layer of the coronavirus family has a lipid layer, which helps in interacting with the host cell (Baglivo et al. 2020).

\section{Possible Solutions to Avoid Transmission}

Since these lipids are hydrophobic and are present in the outer envelope, there is a possibility to break or inactivate these proteins by lipid peroxidation. Sayes et al. (2005) performed the lipid peroxidation by a water-soluble fullerene nano- $\mathrm{C}_{60}$. The fullerene $\left(\mathrm{C}_{60}\right)$ is an allotrope of carbon with antiradical and antioxidant properties (Gacem et al. 2020). These fullerenes are nanoparticles with a hydrophobic character; therefore, they emerge as a colloidal solution when dissolved in water. If the colloidal fullerene solution is illuminated in UVA light, then it produces singlet oxygen $\left({ }^{1} \mathrm{O}_{2}\right)$, which initiates degradation of lipid. This degradation of lipid by the oxidative reaction is known as lipid peroxidation. The deterioration of the lipid layer is dependent on the concentration of fullerene nano- $\mathrm{C}_{60}$. A similar observation of lipid peroxidation by fullerene was made on bacterial phospholipid membrane (Alvarez 2007). Figure 1a shows the illustration of the lipid peroxidation with fullerene coating.

Another possible method is by creating a hydrophobic surface, such that the contact area between the virus and the surface decreases, see Fig. 1b. These types of surfaces have anti-biofouling properties due to their micro-/nanoscale topography that entraps air in the cavity, thereby reducing further adhesion of bacteria (Siddiquie et al. 2020). A typical micro-/nano-scale with microscopic

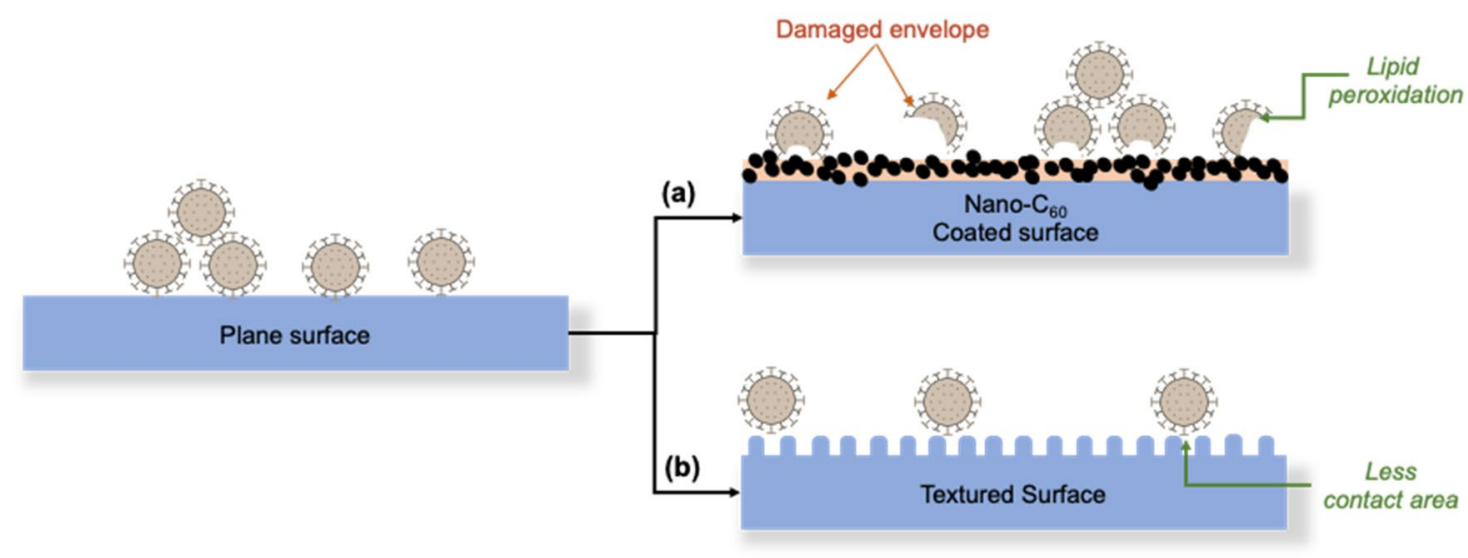

Fig. 1 Two possible methods to fight COVID-19. a By inactivating the lipid layer by coating the surface with nano-C ${ }_{60}$. b By reducing the contact area with the virus by surface texturing 
(a)
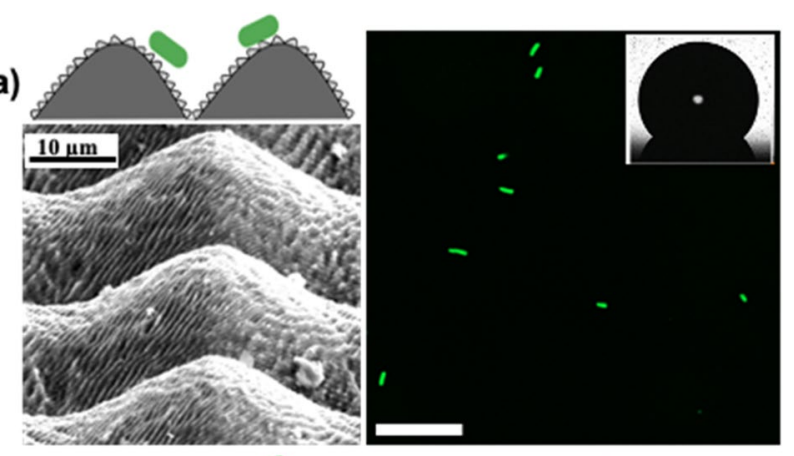

(b)
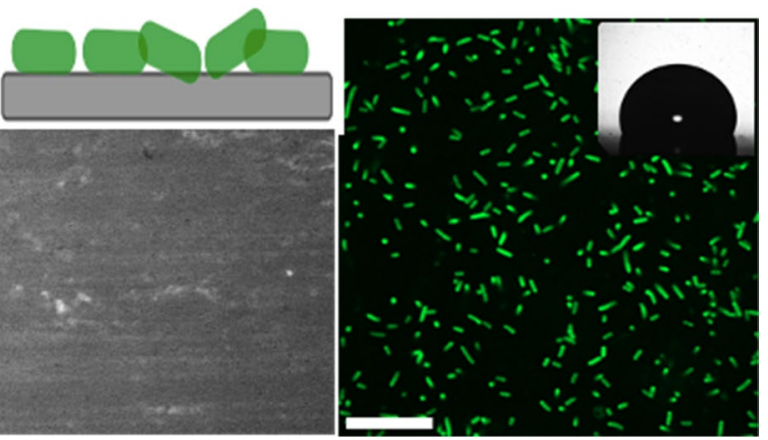

Fig. 2 Effect of surface texturing on anti-biofouling properties: a reduced adhesion on multiscale surface with contact angle $=142^{\circ}$; b adhered E. coli (green) on plain surface with contact angle $=93^{\circ}$, along with SEM image (scale bar $25 \mu \mathrm{m}$ ) (Siddiquie et al. 2020) (color figure online)

texture (pillar) of height $5 \mu \mathrm{m}$ and spacing $40 \mu \mathrm{m}$, superimposed with nano-scale structures of periodicity 800-900 nm fabricated using femtosecond laser on steel substrate is shown in Fig. 2a. Figure 2 b shows a plain steel surface to compare with textured surface for their anti-biofouling properties. The plain surface with contact angle $93^{\circ}$ has larger number of bacteria adhered (see Fig. 2b), as compared to the multiscale surface, as shown in Fig. 2a. The ability to entrap air in between the structures in the multiscale surface has reduced the adhesion of $E$. coli. Since the average size of bacteria is $2 \mu \mathrm{m}$, submicron topography on the surfaces tends to impart them anti-biofouling properties (Whitehead et al. 2006). In the case of COVID-19, the diameter of virus is $60-140 \mathrm{~nm}$ with crone like spikes of size 9-12 nm (Zhu et al. 2020). Therefore, a surface topography with height and spacing less than $60 \mathrm{~nm}$ will possibly decrease contact between the virus and surface effectively, thereby minimizing the adhesion of virus on them.
Figure $3 \mathrm{a}$ shows a decrease in of living cells due to the damage caused by lipid peroxidation (Sayes et al. 2005). The effect of surface roughness and contact angle was examined to check adhesion of E. coli (bacteria), see Fig. 3b (Siddiquie et al. 2020). The decrease in number of bacteria adhered to the nano- and multiscale treated surfaces is due to two reasons. First, due to a decrease in contact area, the microbial adhesion also decreases. Second, if the height and spacing of the topography is less than the size of bacteria or virus, then the surface peaks will pierce the envelope and, hence, the surface will act as antibacterial or antiviral. From the results in both Fig. 3a and b, a decrease in the adhered cells is observed, either by deteriorating the membrane or by reducing adhesion. Matsumoto et al. (2019) prepared hydrophobic sintered ceramic with $\mathrm{La}_{2} \mathrm{Mo}_{2} \mathrm{O}_{9}$ powder, which is toxic to microbes as well as is hydrophobic. Figure $3 \mathrm{c}$ shows the reduction of bacteria (E. coli) as well as virus (bacteriophage $\mathrm{Q} \beta$ ) on $\mathrm{La}_{2} \mathrm{Mo}_{2} \mathrm{O}_{9}$ ceramic with respect to time.

It is concluded from the above discussions that both types of surfaces, i.e., hydrophobic as well as nanocarboncoated, demonstrate beneficial decrease in the surface stability for COVID-19. The surfaces coated with nanocarbon with particles of average size of $60 \mathrm{~nm}$ will be helpful in two ways. They will create a hydrophobic surface with minimum contact area and will also be toxic to lipid layer of the virus.

\section{Conclusions}

This paper presents various causes of transmission of COVID-19, with a brief discussion on structural protein present in the virus. The lipid layer present in the COVID19 can be inactivated by the surfaces coated with nanocarbons. The UVA-illuminated nanocarbon helps in lipid peroxidation. Another aspect of inhibiting transmission is to decrease attachment of the virus by creating hydrophobic surfaces. In this context, fabrication of micro-/ nano-multiscale textured surface could decrease surface stability for COVID-19. These surfaces will minimize adhesion by reducing contact area between the virus and the surface. Also, coating with activated fullerene $\mathrm{C}_{60}$ with size less than $60 \mathrm{~nm}$ will generate a hydrophobic surface, which will have the property to inactivate the lipid layer of COVID-19. 

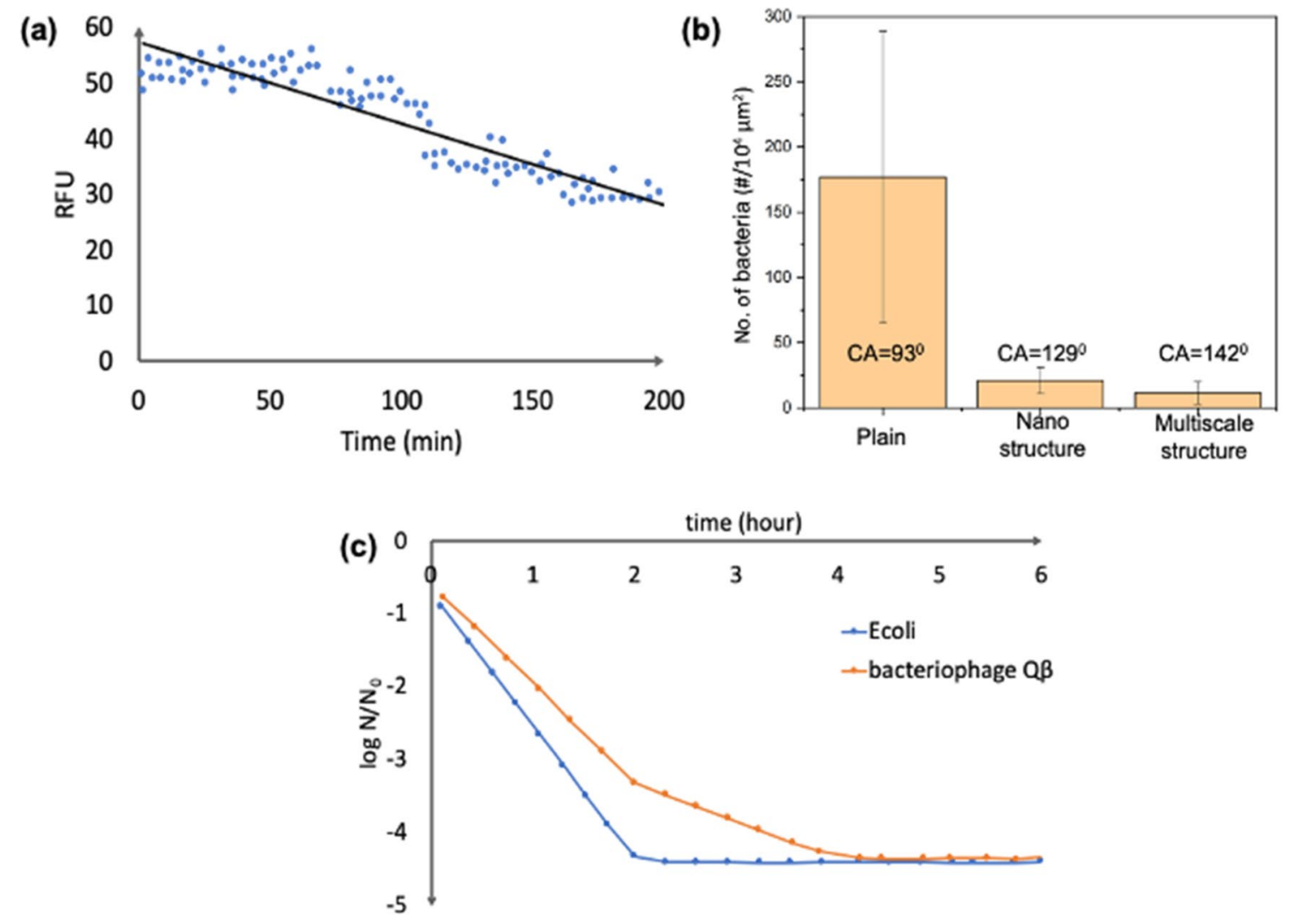

Fig. 3 a Linear decrease in no. of cell with lipid layer, due to lipid peroxidation by fullerene $\mathrm{C}_{60}$ (Sayes et al. 2005); $\mathbf{b}$ decrease in number of bacteria due hydrophobic surface (Siddiquie et al. 2020); c decrease in E. coli (bacteria) and bacteriophage $\mathrm{Q} \beta$ (virus) due to hydrophobic (Matsumoto et al. 2019).

\section{References}

Alvarez PJJ (2007) Effect of a fullerene water suspension on bacterial phospholipids and membrane phase behavior. Environ Sci Technol 41(7):2636-2642

Baglivo M, Baronio M, Natalini G, Beccari T, Chiurazzi P, Fulcheri E, Petralia P, Michelini S, Fiorentini G, Abele G (2020) Natural small molecules as inhibitors of coronavirus lipid-dependent attachment to host cells: a possible strategy for reducing SARSCOV-2 infectivity ? Acta Biomed 91:161-164. https://doi. org/10.23750/abm.v91i1.9402

Editor Letter (2020) Aerosol and surface stability of SARS-CoV-2 as compared with SARS-CoV-1. N Engl J Med 382:1564-1567. https://doi.org/10.1056/NEJMc2004973

Gacem MA, Gacem H, Ould-El-Hadj-Khelil A (2020) Nanocarbons: antibacterial, antifungal, and antiviral activity and the underlying mechanism. Carbon nanomaterials for agri-food and environmental applications. Elsevier Inc, Amsterdam. https://doi.org/10.1016/ b978-0-12-819786-8.00022-0

Huang C, Wang Y, Li X, Ren L, Zhao J, Yi Hu, Zhang Li, Fan G, Jiuyang Xu, Xiaoying Gu (2020) Articles clinical features of patients infected with 2019 novel coronavirus in Wuhan, China. Lanchet J. https://doi.org/10.1016/S0140-6736(20)30183-5

Kirchdoerfer RN, Cottrell CA, Wang N, Pallesen J, Yassine HM, Turner HL, Corbett KS, Graham BS, McLellan JS, Ward AB (2016) Pre-fusion structure of a human coronavirus spike protein. Nature 531(7592):118-121. https://doi.org/10.1038/nature17200
Liu J, Liao X, Qian S, Yuan J, Wang F, Liu Y, Wang Z et al (2020) Community transmission of severe acute respiratory syndrome coronavirus. Emerg Infect Dis 26(6):4-8

Matsumoto T, Sunada K, Nagai T, Isobe T, Matsushita S (2019) Preparation of hydrophobic La 2 Mo $2 \mathrm{O} 9$ ceramics with antibacterial and antiviral properties. J Hazard Mater 378(June):120610. https ://doi.org/10.1016/j.jhazmat.2019.05.003

McBride R, van Zyl M, Fielding BC (2014) The coronavirus nucleocapsid is a multifunctional protein. Viruses 6(8):2991-3018. https://doi.org/10.3390/v6082991

Neuman BW, Kiss G, Kunding AH, David Bhella M, Baksh F, Connelly S, Droese B et al (2020) A structural analysis of M protein in coronavirus assembly and morphology. J Struct Biol J. https:// doi.org/10.1016/j.jsb.2010.11.021

Phan T (2020) Infection, genetics and evolution novel coronavirus: from discovery to clinical diagnostics. Infect Genet Evol 79(January):104211. https://doi.org/10.1016/j.meegid.2020.104211

Sayes CM, Gobin AM, Ausman KD, Mendez J, West JL, Colvin VL (2005) Nano-C60 cytotoxicity is due to lipid peroxidation. Biomaterials 26(36):7587-7595. https://doi.org/10.1016/j.biomateria 1s.2005.05.027

Schoeman D, Fielding BC (2019) Coronavirus envelope protein: current knowledge. Virol J 16(1):1-22. https://doi.org/10.1186/s1298 5-019-1182-0

Siddiquie RY, Gaddam A, Agrawal A, Dimov SS, Joshi SS (2020) Antibiofouling properties of femtosecond laser-induced submicron 
topographies on elastomeric surfaces. Langmuir. https://doi. org/10.1021/acs.langmuir.0c00753

Song HC, Seo M-Y, Stadler K, Yoo BJ, Choo Q-L, Coates SR, Uematsu $Y$ et al (2004) Synthesis and characterization of a native, oligomeric form of recombinant severe acute respiratory syndrome coronavirus spike glycoprotein. J Virol 78(19):10328-10335. https://doi.org/10.1128/JVI.78.19.10328

Tong Y, Ph D, Ruiqi Ren M, Med KSM, Leung DPh, Lau EHY et al (2020) Early transmission dynamics in wuhan, china, of novel coronavirus-infected pneumonia. N Engl J Med. https://doi. org/10.1056/NEJMoa2001316

Venkatagopalan P, Daskalova SM, Lopez LA, Dolezal KA, Hogue BG (2015) Coronavirus envelope (E) protein remains at the site of assembly. Virology 478:75-85. https://doi.org/10.1016/j.virol 2015.02.005

Whitehead KA, Rogers D, Colligon J, Wright C, Verran J (2006) Use of the atomic force microscope to determine the effect of substratum surface topography on the ease of bacterial removal. Colloids Surf B 51(1):44-53. https://doi.org/10.1016/J.COLSU RFB.2006.05.003
WHO Situation Report (2020a) Coronavirus disease 2019 (COVID19), Issue 78

WHO Situation Report (2020b) Coronavirus disease 2019 (COVID19), Issue 72

Zhao S, Lin Q, Ran J, Musa SS, Yang G, Wang W, Lou Y et al (2020) Preliminary estimation of the basic reproduction number of novel coronavirus (2019-NCoV) in China, from 2019 to 2020: a datadriven analysis in the early phase of the outbreak. Int J Infect Dis 92:214-217. https://doi.org/10.1016/j.ijid.2020.01.050

Zhu Na, Zhang D, Wang W, Li X, Yang Bo, Song J, Zhao X et al (2020) A novel coronavirus from patients with pneumonia in China, 2019. N Engl J Med 382(8):727-733. https://doi.org/10.1056/ NEJMoa2001017

Publisher's Note Springer Nature remains neutral with regard to jurisdictional claims in published maps and institutional affiliations. 